\title{
On the drought in the Balearic Islands during the hydrological year 2015-2016
}

\author{
Climent Ramis, Romualdo Romero, Víctor Homar, Sergio Alonso, Agustí Jansà, and Arnau Amengual \\ Meteorology Group, Department of Physics, University of the Balearic Islands, 07122 Palma, Spain \\ Correspondence: Climent Ramis (cramis@uib.es)
}

Received: 20 June 2017 - Discussion started: 30 June 2017

Revised: 16 October 2017 - Accepted: 12 November 2017 - Published: 21 December 2017

\begin{abstract}
During the hydrological year 2015-2016 (September to August) a severe drought affected the Balearic Islands, with substantial consequences (alleviated partially by desalination plants) on water availability for consumption from reservoirs and aquifers and also on the vegetation cover. In particular, a plague of Xylella fastidiosa reached an alarming level for almond and olive trees. The expansion of this infestation could be attributed to, or at least favored by, the extreme drought. In this paper we analyze this anomalous episode in terms of the corresponding water balance in comparison with the balance obtained from long-term climatological data. It is shown that the drought was the result of a lack of winter precipitation, the lowest in 43 years, which led to a shortage of water storage in the soil. In several meteorological stations analyzed, evaporation was greater than precipitation during all the months of the year. In terms of attribution, it is found that during the 2015-2016 winter the atmospheric circulation over the North Atlantic was largely westerly and intense, with high values of the NAO index that were reflected in high pressures over the Iberian Peninsula and the western Mediterranean.
\end{abstract}

\section{Introduction}

The Balearic Islands are located in the central part of the western Mediterranean basin (Fig. 1). The archipelago presents a well-marked interannual variability in the annual precipitation, as shown by Homar et al. (2010). Within this interannual variability, a particularly severe drought episode occurred during the hydrological year (September to August) 2015-2016. The drought affected the eastern part of the Iberian Peninsula, as reported by the Spanish
Meteorological Agency (AEMET, http://www.aemet.es/es/ serviciosclimaticos/vigilancia_clima/). However, we restrict this study to the Balearic Islands, where the population of perennials suffered a remarkable mortality, especially among almond, olive and other fruit trees. Shrubs and other plants such as bushes and steppes also perished mostly in the southern part of the archipelago, especially young individuals with very shallow roots. In addition, a plague of Xylella fastidiosa spread after the summer of 2016, and this could be attributed to, or at least bolstered by, the drought and further hydrological stress suffered by the almond and olive trees. Although it is difficult to assess quantitatively the total losses resulting from the drought (these may have reached more than EUR 10 million in livestock breeding due to loss of up to $90 \%$ of the production of forage, according to the Diario de Mallorca newspaper, 4 June 2017), different lines of funding were issued by the regional government. Besides the impacts on the natural and agricultural systems, the demand for water for personal and leisure consumption reached its historical maximum during the summer of $2016\left(36.5 \times 10^{6} \mathrm{~m}^{3}\right.$ during August 2016 in Mallorca, according to same newspaper), when the islands registered a record number of tourists (more than 10.9 million in Mallorca). All together this left the reservoirs and aquifers of the islands at concerning levels, putting at serious risk the supply for the following months in case of drought persistence without the help of the desalination plants. This severe drought can be framed in the context of the observed increase in the frequency of droughts in the Mediterranean area (Hoerling et al., 2012) and in particular in the Spanish eastern lands (Vicente-Serrano et al., 1994).

The lands to the north, east and west of the Mediterranean Sea have a climate that is characterized by a mild and rainy winter and a warm and dry summer. According to the classi- 


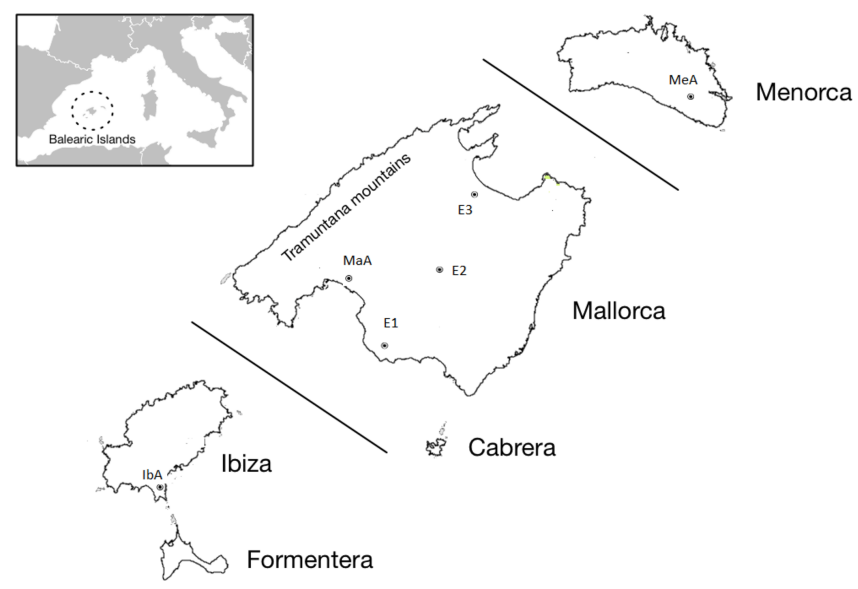

Figure 1. The Balearic Islands: $\mathrm{MaA}$ is the Mallorca airport; $\mathrm{MeA}$ is the Menorca airport; IbA is the Ibiza airport. Locations of the other climatological stations analyzed in the text are also indicated.

fication of Köppen these are thus considered to have a Csatype climate (Peel et al., 2007). This type takes the generic name of "Mediterranean climate". The Köppen classification global map is determined from gross climatic features; when analyzing the data at higher resolution, noticeable differences are found, even between contiguous areas of reduced extent. The Balearic Islands (Fig. 1), with a typical Mediterranean climate, is a specific example of a context exhibiting notable climatic differences within a relatively small region. Given the size of the islands (Mallorca, the largest, extends over $3640 \mathrm{~km}^{2}$ ), among all the influencing factors we must attribute the greatest part of observed climatic differences over the territory to the orography. These contrasts are indeed quite accentuated in the archipelago. The four major islands of the Balearics have similar patterns of mean monthly rainfall but the spatial distribution of annual totals is heterogeneous. Menorca and Ibiza-Formentera show a remarkable spatial uniformity, with mean annual values higher in Menorca than in Ibiza-Formentera (Guijarro, 1986; Jansà, 2014; López et al., 2017). These wetter conditions are attributed to the higher latitude of Menorca; the island is more frequently affected by the fronts linked to the low-pressure disturbances that evolve through central Europe and by the lows developed over the Genoa Gulf. In Mallorca there is high spatial contrast in the mean annual distribution of precipitation. Along the southern coasts, where the orography is practically absent, annual precipitation values are of the order of $350 \mathrm{~mm}$ on average, while in the zones with the highest mountains (Tramuntana range, heights up to $1500 \mathrm{~m}$; see Fig. 1), in the northwest of the island, the average annual rainfall reaches $1400 \mathrm{~mm}$ (Guijarro, 1986). These large contrasts occur within a distance of about $50 \mathrm{~km}$. In fact, regarding the climatic characteristics of the south of Mallorca, it conforms to BSk type from the classification of Köppen; that is, winters are temperate, not excessively dry and have very

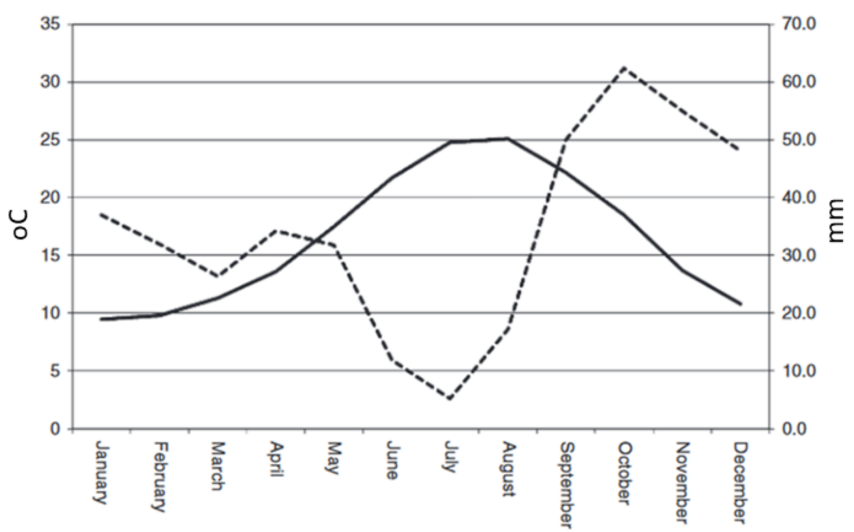

Figure 2. Ombrothermic diagram (Gaussen, 1955) for the Mallorca airport (1981-2010) (after Jansà et al., 2017). The continuous line is the mean temperature. The dashed line is the mean precipitation.

dry and torrid summers. The northern and northeastern zones of Mallorca receive precipitation of the same order as those of Menorca, once again clearly above the accumulations of the southern region.

Another characteristic of the rainfall over the Balearic Islands is its marked seasonality. The ombrothermic diagram for the Mallorca airport (Fig. 2; Jansà et al., 2017) shows the most outstanding features of the Mediterranean climate: the abovementioned scarcity of precipitation during the summer, the relatively high temperatures during this period of the year and the mild and relatively wet autumn and winter. Ending a hot summer after 2 months with almost no precipitation somehow characterizes the type of vegetation present in the lowlands (pines, shrubs, bushes and steppes but also almond trees). At the same time, the islands have an economy fundamentally dependent on tourism (in 2016, Balearic airports received 36.8 million passengers, according to the official web pages of the three airports) that is mainly concentrated in the summer months. The supply of drinking water during this period depends critically on underground aquifers (and on the supplementary action of desalination plants) since existing reservoirs in the rainiest mountainous area of Mallorca are too small. After the long and extreme summer, the recovery of the aquifers is strongly determined by the amount of rainfall received during the autumn and the following winter. The flora will be subjected to greater or lesser hydric stress depending mainly on the behavior of autumn rainfall. The occurrence of large water stress situations is not uncommon given the high interannual variability that characterizes annual precipitations in the Balearic Islands (Homar et al., 2010). Extreme manifestations of such variability are not new; there are written references about important droughts affecting the archipelago during the Middle Age (Barceló, 1991) as well as many oral references to the hazardous drought that occurred during 1912-1913 in Mal- 
lorca, a time when the local economy was almost exclusively dependent on agriculture.

Given the strong water deficit imposed on the vegetation by the end of the summer and also the natural cycle of the underground aquifers, it may be more suitable to analyze precipitation in terms of the hydrological year (September to August). Additionally, in order to account for the vegetation stress in more detail, it becomes more informative to calculate the annual water balance in which precipitation and evaporation are presented together (considering for the latter the potential evapotranspiration, EVT) and to compare it with the climatic water balance for which the local vegetation has adapted.

This paper presents in Sect. 2 the interannual variability of the precipitation regime in the Balearic Islands, from both the standard and hydrological year perspectives, as well as the climatic water balance of the region. Section 3 discusses the water balance for the hydrological year 2015-2016 in detail. In Sect. 4 the circulation pattern of the exceptional context that led to the severe drought of that year is analyzed and compared with the pattern of an illustrative wet year. Finally, Sect. 5 presents the main findings and conclusions of the study.

\section{Precipitation variability and climatic water balance}

Monthly precipitation values at Mallorca, Menorca and Ibiza airports from 1973 to 2016 (44 years) have been analyzed. These are the longest climatic series without gaps in the Balearic Islands. From the monthly values, annual accumulations as well as those corresponding to the 43 hydrological years from 1973-1974 to 2015-2016 have been calculated.

The anomalies of the annual rainfall with respect to the average of the reference period 1981-2010 for the airports of Mallorca, Menorca and Ibiza have been considered (not shown). The yearly mean for the reference period at Mallorca is $411.3 \mathrm{~mm}$ and the interannual variability of the series is large enough as to yield a standard deviation of $100.9 \mathrm{~mm}$ (coefficient of variation $\mathrm{CV}=24.5 \%$ ). The average for Menorca airport is $548.6 \mathrm{~mm}$ and the standard deviation is $132.8 \mathrm{~mm}(\mathrm{CV}=24.2 \%)$. These values for Ibiza are 411.1 and $117.3 \mathrm{~mm}(\mathrm{CV}=28.5 \%)$. These relatively large values of the coefficients of variation reveal the high interannual variability of precipitation in the islands, which is itself related to the variability of the atmospheric patterns, as shown in Sect. 4.

As revealed by the $\mathrm{CV}$ values, the variability is greater in Ibiza than in Menorca, although there are anomalies in both stations that occasionally exceed $200 \mathrm{~mm}$. It is noteworthy the relatively low correlation (0.54) that exists between the time series of Mallorca and Menorca, but especially low is the correlation between the time series of Menorca and Ibiza (0.30). For Mallorca and Menorca there are few cases in
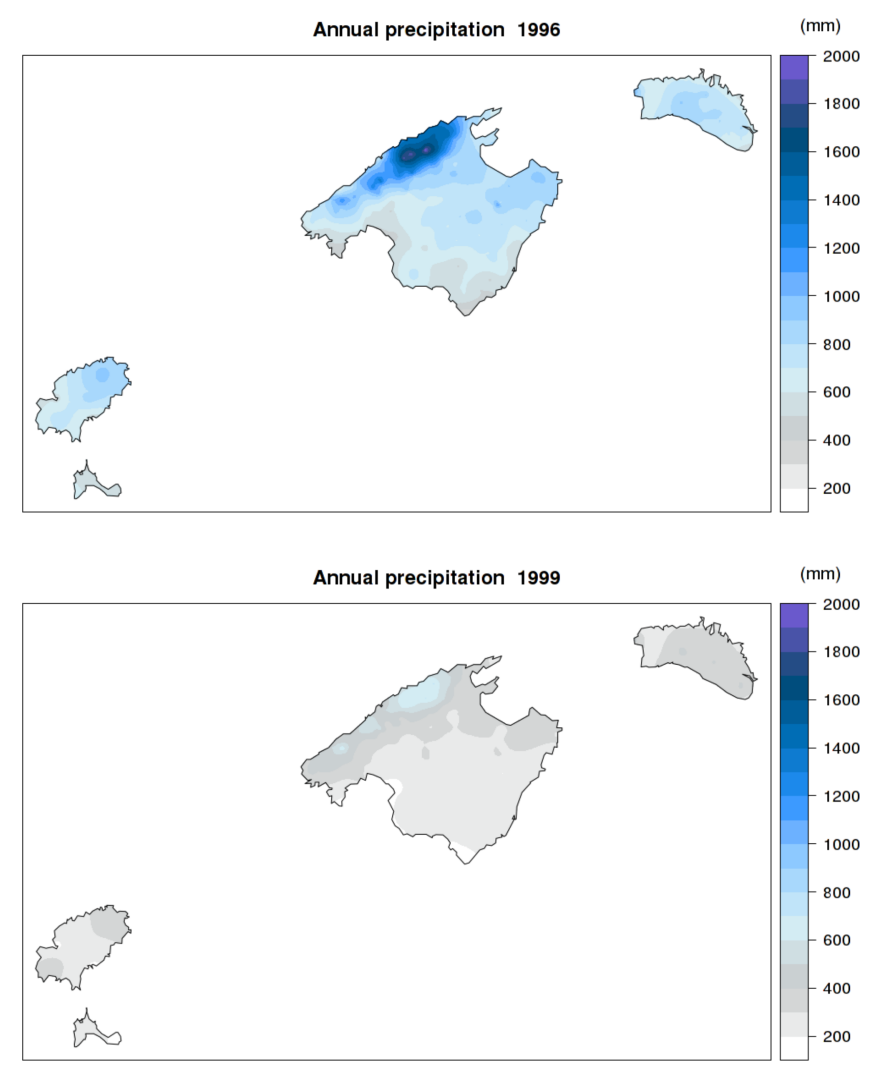

Figure 3. Spatial distribution of accumulated precipitation for 1996 (wet year) and 1999 (dry year). The same scale is used (from http: //pregridbal-v1.uib.es/).

which a positive anomaly in one station does not correspond to the same sign in the other. One of such cases is 2016, when the intense rainfall recorded in Mallorca during the months of October and December (107.6 and $150.4 \mathrm{~mm}$, respectively) explains the positive anomaly of its airport; however, this event did not affect Menorca (13.2 and $79.8 \mathrm{~mm}$, respectively).

It should be noted that a wet (dry) year at the airports tends to be accompanied by greater (lower) than normal annual precipitation in the rest of each respective island. Figure 3 shows this kind of distribution for the years 1996 and 1999 , considered as wet and dry years, respectively. However, some kind of objective index should be applied to analyze the representativeness of the interannual variability of the rainfall captured by the airports, especially in Mallorca, where the spatial variability of the annual rainfall is very high as previously indicated (López et al., 2017). An analysis of the spatial representativeness of the interannual variability captured by the Mallorca airport has been performed using two methodologies. First, the time series of the relative annual anomalies (anomaly divided by the corresponding annual average) have been calculated for five meteorological stations located in Mallorca, and the resulting mean time series (of the five individual series) has been determined. The five sta- 


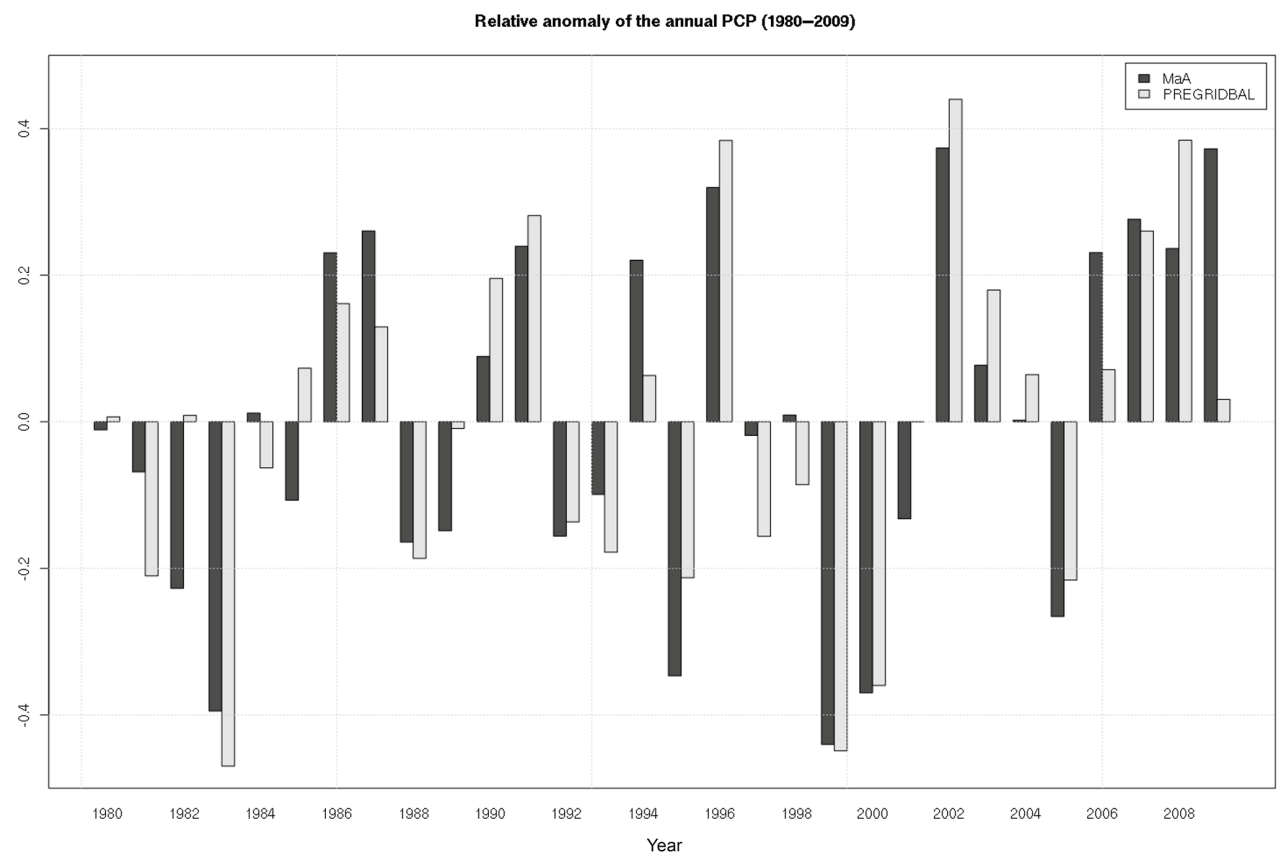

Figure 4. Time series of the relative annual precipitation anomalies at the Mallorca airport and for Mallorca as a whole derived from the PREGRIDBAL project.

tions are representative of different pluviometric regimes of the island: mountainous area, north, center, east and south. For this analysis, the period 1981-2010 has been considered. The time series of annual relative anomalies at Mallorca airport has been compared against the above mean time series. The time series exhibit a correlation coefficient as high as 0.9 . The second method is analogous to the previous one but uses the precipitation analyses across the island of Mallorca that were derived in the PREGRIDBAL project (López et al., 2017). These analyses have a resolution of $100 \mathrm{~m}$ and use all available observed data for each product requested. Annual precipitation grid data have been considered for each of the years 1980-2009, together with the grid analysis of mean precipitation corresponding to these 30 years. For each grid point and for each year the relative annual anomalies have been determined and a time series expressing the spatial average of annual anomalies has been calculated. Finally, this time series has been compared against the relative anomalies at Mallorca airport, yielding in this case a correlation coefficient of 0.86 (Fig. 4). Thus, it seems well justified the assumption that the spatial-temporal variability in the island of Mallorca is correctly captured by the series of precipitations at the Mallorca airport.

Due to their relatively small size and moderate orography, the spatial variabilities of the annual mean precipitation in Menorca and Ibiza are much lower than in Mallorca; therefore it seems clear that the corresponding time series at the airports are even more representative of the corresponding interannual variability of the whole islands.
Figure 5 shows the precipitation anomalies at the airports of Mallorca, Menorca and Ibiza for the hydrological years 1973-1974 to 2015-2016 (43 years) with respect to the reference period 1980-1981 to 2009-2010. Recall the hydrological year comprises from September to August. The mean precipitation for the reference period in Mallorca is $409.5 \mathrm{~mm}$, with a standard deviation of $119.2 \mathrm{~mm}$ $(\mathrm{CV}=29.1 \%)$. For Menorca these values are 544.3 and $120.5 \mathrm{~mm}(\mathrm{CV}=22.1 \%)$, and for Ibiza they are 413.0 and $116.6 \mathrm{~mm}(\mathrm{CV}=28.2 \%)$, respectively. Mean values are very similar with respect to the observations derived from the "standard" or natural years but the interannual variability is higher now in Mallorca and lower in Menorca. In the present case there is a greater correlation $(0.68)$ between the anomalies of these two rainfall stations. In Ibiza the values are very similar to those obtained for the natural year. The correlation between the time series of Menorca and Ibiza is identically low ( 0.33 vs. 0.30 for the natural years). These low correlations values are a clear manifestation that the rainbearing meteorological systems for the north and south of the archipelago do not respond to the same circulation patterns, as previously reported by Guijarro (2002, 2003). A detailed study on the surface circulation related with daily rainfall patterns in Mallorca can be found in Sumner et al. (1995).

Looking at Fig. 5, it can be observed that dry hydrological years leading to water stress on the flora, and probably on the aquifers, become clearly distinguishable. The periods 1981 to 1984,1991 to 1994 and 1998 to 2001 are noteworthy. 

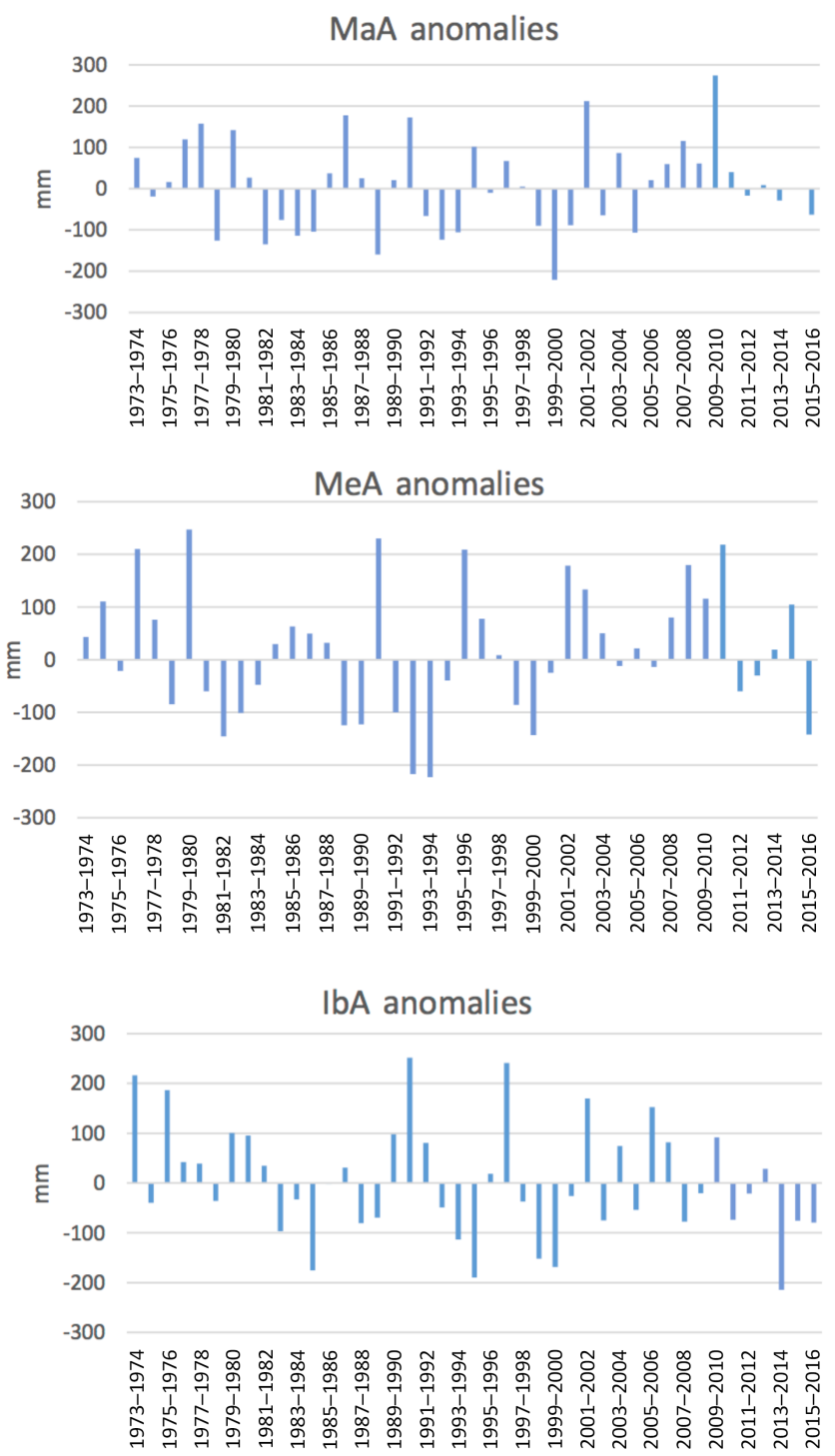

Figure 5. Anomalies of the precipitation for the hydrological year at the airports of Mallorca Menorca and Ibiza with respect to the respective averages calculated for the reference period 1980-1981 to 2009-2010.

It can be observed that in 2015-2016 there are also negative anomalies that are much more important in Menorca.

Although there are several indices to characterize a drought (e.g., the Palmer Drought Severity Index (PDSI), Palmer, 1965; the Standardized Precipitation Index (SPI), McKee et al., 1993; Supply Demand Index (SDDI), Rind et al., 1990), from an ecological point of view and in order to account for the possible water stress on the flora, it is interesting to analyze the water balance directly, in which the precipitation is compared against the evaporation, month by month, and from this balance to evaluate the periods of the year in which there is an excess or lack of water in the soil. In this sense there are studies on the effects of droughts on the Mediterranean flora in Spain (e.g., Peñuelas et al., 2001).
The determination of the potential evapotranspiration (PET) is an important step when estimating soil water deficit or excess. However, empirical formulas for estimating PET have their limitations, and the results cannot be considered at the same level of exactitude as precipitation measurements. In consequence, the comparison between precipitation and PET has to be regarded as an approximation to the reality. The existence of several analytical expressions to calculate PET using different variables also demonstrates the difficulty to determine this magnitude accurately.

Estimation of the climatic water balances at the three airports was carried out using the Thornthwaite method (1948) for the determination of monthly PET, using monthly mean temperature and precipitation values referred to the reference period 1981-2010. In our analysis, actual evaporation is considered to coincide with calculated PET when monthly precipitation is greater than PET, and in these circumstances the remaining precipitation is converted to water stored in the soil. These amounts can be cumulative through the year and, if the total storage reaches a value which is considered to be the maximum capacity of the soil, the excess becomes surface runoff and infiltration. The maximum storage of the soil depends on several factors, e.g., the texture, land use and slope of the terrain. Botey and Moreno (2015) have produced a map of the soil maximum storage for the Iberian Peninsula and the Balearic Islands. From the information displayed in their map, for the lowlands of the Balearic Islands where the used meteorological stations are located, $100 \mathrm{~mm}$ can be considered a reasonable value. If the monthly precipitation is less than the PET, then the actual evaporation is equal to the precipitation plus the reserve portion of the soil moisture that is needed, until it is exhausted. The remaining difference between PET and actual evaporation is indicative of the water deficit that has to be overcome by vegetation. Balance calculations begin in the month of September, considering that the soil does not contain any water after the dry summer.

Figure 6 shows the climatic water balance (1981-2010) during the hydrological year, according to the indicated method, for the airports of Mallorca, Menorca and Ibiza. Climatologically, there is deficit in Mallorca for the first month of September. There is storage of water in the soil from October to February, which is totally exhausted by the end of June. During the summer (June-August) the deficit is very large, reaching $150 \mathrm{~mm}$. At the Menorca airport there is also a deficit in September, the accumulation of water in the soil begins in October, and there is runoff or/and infiltration during January, February and March. The water stored in the soil of Menorca allows for evaporation to be larger than precipitation even in June, with a total lack of soil water observed only in July and August. The maximum deficit also reaches $150 \mathrm{~mm}$. At Ibiza the water balance is very similar to Mallorca but the storage of water in the soil during the winter is lower and therefore it is consumed more quickly, inducing a large deficit during all the summer. 

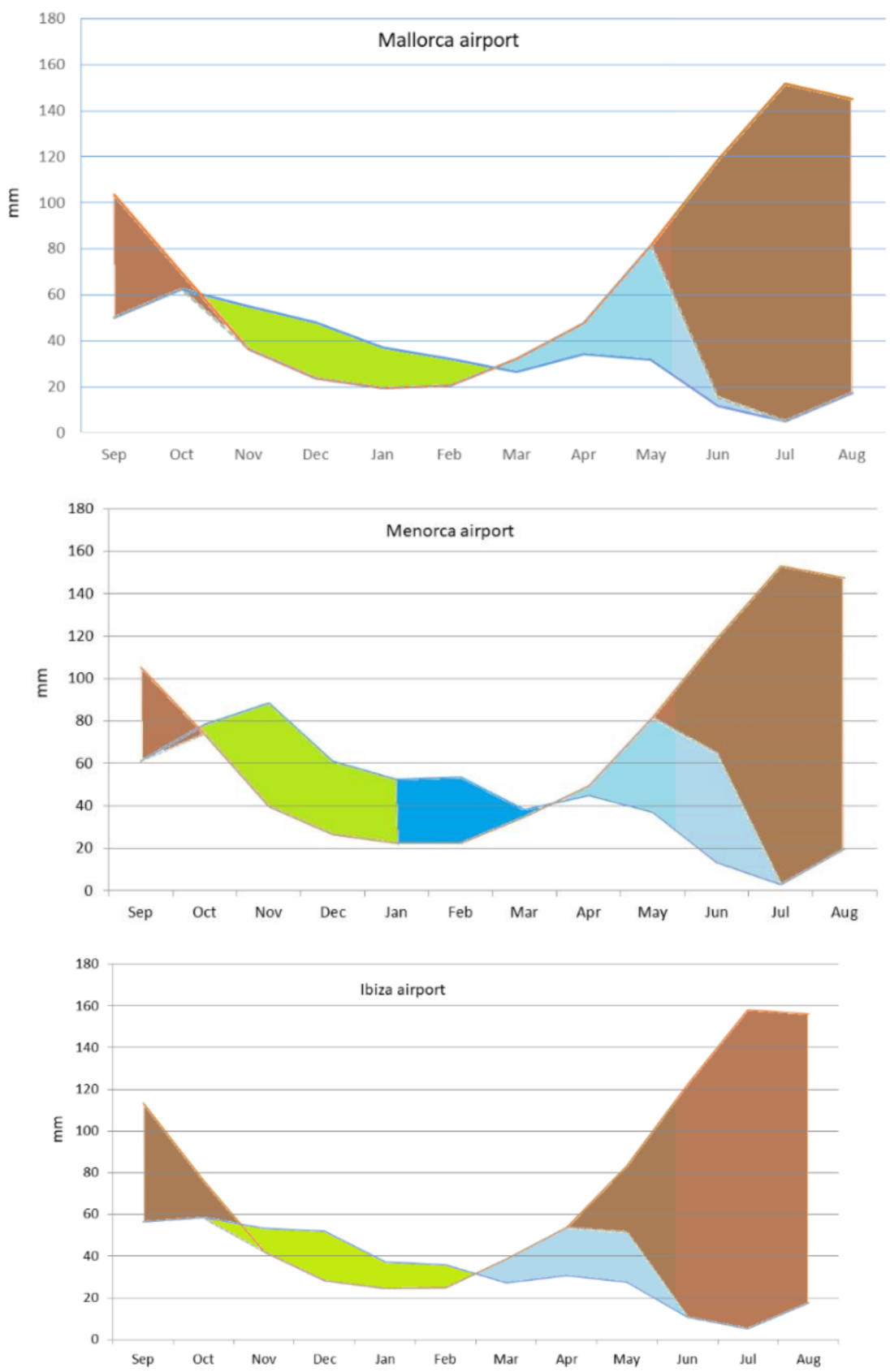

Figure 6. Climatic water balance (1981-2010) at the airports of Mallorca, Menorca and Ibiza (MaA, MeA and IbA in Fig. 1). Lines: blue is precipitation $(\mathrm{mm})$; brown is potential evapotranspiration $(\mathrm{mm})$; dashed green is evaporation $(\mathrm{mm})$. Colored areas: green is the accumulation of water in the soil; cyan is the evaporation of water stored in the soil; blue is runoff; brown is the water deficit in the soil.

The climatic water balance at Menorca and Ibiza airports can be considered representative of the whole islands. In contrast, for the larger and more complex island of Mallorca it is evident, bearing in mind Fig. 3 and the results of Guijarro (1986) and Jansà (2014), that the water balance of the airport cannot, in any way, be extended to the whole island. The water balance shown is representative of the south of Mallorca. It is also indicative of the situation in the western and eastern coastal zones and in the center of the island, al- though the latter zone tends to store a little more water in the soil during the winter as a consequence of the higher precipitation (recall Fig. 3). For the northern and northeastern zones of Mallorca the water balance is expected to be much more similar to that at the Menorca airport, as the rainfall regimes are quite similar in monthly distributions and amounts. In the mountainous area of Mallorca the water balance is certainly very different to that at the airport, as the climatological annual precipitation is almost 4 times greater. In this zone there 
are two reservoirs dedicated to the supply of water to the population, which of course rely on the regular runoff of the autumn and winter. In any case, some drought also exists on the mountains during the summer, since precipitation in this season is basically absent as in the lowlands.

In order to validate the previous water balance in terms of precipitation and PET, the results of a more sophisticated method have been examined. The data provided from the website https://wci.earth2observe.eu/portal/ (which collects data from the European Earth2Observe project) at the three grid points (resolution $0.25^{\circ}$ ) closest to the airports of Mallorca, Menorca and Ibiza have been obtained. Monthly total precipitation values (PCP) for each grid point have been extracted from 1981 to 2010 and the mean monthly values have been computed (these monthly data originally come from the analysis performed by Beck et al., 2017). Monthly total values of EVT (i.e., surface evaporation, interception and transpiration) and monthly total runoff ( $R$; i.e., surface runoff, sub-surface flow and deep percolation) provided by the eight available models have also been obtained from the Earth2Observe website. For each model and variable, the mean monthly values with reference to 1981-2010 have been calculated. Finally, the eight models' ensemble mean and inter-model standard deviation of the previous monthly values were obtained. With these values the water balance was estimated at each of the three mesh points considered. This balance is built as the precipitation minus the actual evapotranspiration minus the losses $(\mathrm{WB}=\mathrm{PCP}-\mathrm{EVT}-R)$.

These results reveal the following:

a. For the mesh point near the Mallorca airport (components of the water balance and the balance itself are displayed in Fig. 7) the precipitation values used by the models are much higher than those observed at the airport. As an example, the observed mean annual value (1981-2010) is $411.3 \mathrm{~mm}$, while the same rainfall product used by the models is $597.4 \mathrm{~mm}$. Regarding EVT, the model ensemble mean values are higher than those obtained at the Mallorca airport for PET using the Thornthwaite formula, especially in summer. The monthly standard deviations are very high (that is, large differences among the different models). The PET for the Mallorca airport lies within the ensemble spread region. Regarding the water balance, and accepting $100 \mathrm{~mm}$ as saturation threshold for the soil, saturation in the Earth2Observe data is obtained during December, January and February and may be due to the high precipitation values ingested in the models. Dryness is obtained in July and August and very low water reserve values in June and September. In the former results, a remarkable water deficit is obtained in September (Fig. 6), because the temperatures are still high.

b. For the grid point near Menorca airport (not shown), the monthly values of precipitation used by the models are much more similar to those observed at the airport (reg- istered annual average of $548.6 \mathrm{~mm}$ versus $601.2 \mathrm{~mm}$ in the models). The EVT shows a behavior similar to that at the grid point near the airport of Mallorca: values are greater than those of PET obtained from the Menorca airport data using the Thornthwaite expression, and there is a large spread among the eight models. The calculated PET values are also well encompassed by the ensemble dispersion band. Regarding the water balance, saturation of the soil is obtained in January and February and a value close to saturation in December. Dryness is also obtained in July and August. These results are very similar to those obtained directly in our study for the Menorca airport.

c. For the grid point close to the Ibiza airport (not shown), the average monthly precipitation values used by the models are also significantly higher than those registered at the Ibiza airport (observed annual mean of $411.1 \mathrm{~mm}$ versus $497.2 \mathrm{~mm}$ in the models). Again the average EVT values of the ensemble are larger than PET values given by the Thornthwaite's expression at the Ibiza airport. The inter-model spread is very high. Regarding the water balance, saturation of the soil is not reached in any month; in contrast, dryness is present during May, June, July and August. These results are in agreement with the results obtained directly with the airport data.

In conclusion, it seems that the simple method used in the paper is sufficient to obtain a clear representation of the drought object of the study.

\section{Hydrologic year 2015-2016}

As already mentioned, the hydrological year 2015-2016 was characterized by a negative anomaly with respect to the reference period (Fig. 5). Other hydrological years exhibit greater negative anomalies, but it was the widespread deficit of precipitation during 2015-2016 what characterizes the hazardous effects of this drought event. Figure 8 presents the hydrological balance for Mallorca, Menorca and Ibiza airports corresponding to that hydrological year. For these water balances, daily PET has been calculated using the Hargreaves method (Hargreaves and Samani, 1985). The monthly values have been obtained from the daily values. The distribution of rainfall shows significant accumulations in September due to the convective rains that affected the islands $(176.4 \mathrm{~mm}$ in Mallorca, 181.1 in Menorca and 139.6 in Ibiza). The quite low rainfall recorded during the rest of the hydrologic year, particularly during the rest of the autumn and the whole winter, is also evident. At Mallorca airport the precipitation during November 2015 to January 2016 was $25.6 \mathrm{~mm}$, which represents the lowest value among the 43 considered hydrologic years (Fig. 9). Similarly, the total precipitation recorded during December 2015 was $0.2 \mathrm{~mm}$, the lowest of 

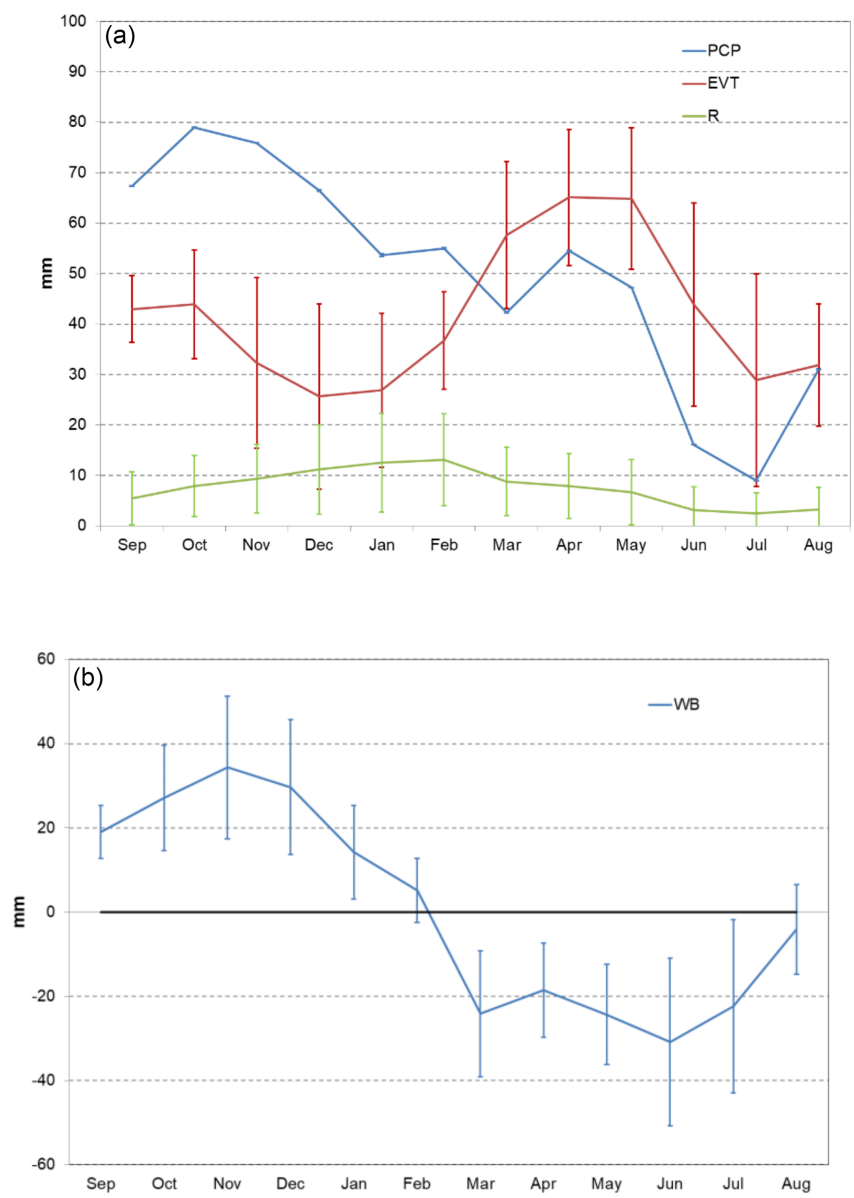

Figure 7. (a) Components of the climatic water balance (19812010) at the grid point nearest to the Mallorca airport, deduced using data from the European Earth2Observe project. Vertical bars represent standard deviation among the eight models. (b) Water balance at the same grid point (see text for details).

this month for the whole period 1973-2016. At Menorca airport the accumulated precipitation from November 2015 to January 2016 was $45 \mathrm{~mm}$, also the lowest quantity recorded in a hydrologic year. The precipitation for December 2015 was $2.1 \mathrm{~mm}$, again the minimum record for this month during the period 1973-2016. In Ibiza the situation was similarly extreme, since $35.2 \mathrm{~mm}$ was the precipitation recorded for November-January, the lowest for the 43 analyzed hydrologic years, and only $0.7 \mathrm{~mm}$ was registered in December 2015 (only surpassed by the $0.2 \mathrm{~mm}$ recorded in 1974).

For the Mallorca airport (Fig. 8) it is observed that, during the month of October, the water that was stored in the soil as consequence of the heavy precipitation events of September was already consumed; during the rest of the year there is a deficit. The lack of precipitation during the winter months implies a very dry soil on sunny days and a rise of temperatures established in spring.

Something similar happens in Ibiza, where the water deficit starts a bit later than in Mallorca as a consequence of the rainy early autumn (September and October) but where the abnormal lack of winter rains is also quite remarkable. In Menorca the situation is to some extent similar: the deficit begins in March, although the winter precipitation was also very scarce.

The Thornthwaite approach applied to obtain PET monthly climatic values uses the monthly mean temperatures provided by AEMET for the period 1981-2010. The aim is to build a reference water balance for a comparison with the particular water balance of the hydrological year 2015-2016. For this hydrological year, the PET monthly values have been calculated from the daily values obtained by the Hargreaves method. Some comparison between the two methods for this year is necessary to fully justify the reference to the climatic water balance. A comparison between both methods was made. Specifically, monthly PET values using the Thornthwaite method were calculated for the hydrological years 2014-2015 and 2015-2016 at the E1 site in Mallorca (see Fig. 1). Analogous monthly values were obtained from the daily PET values given by the Hargreaves formula. The E1 station is located in the most arid region of the island. The two time series show a correlation coefficient of 0.9 (see Fig. 10). For the warmer (colder) months the Thornthwaite method reveals larger (lower) monthly PET values than the other approach. In any case, given the high value of the correlation coefficient, the obtained reference or climatic water balance can be effectively compared with the one calculated for the 2015-2016 hydrological year.

Comparing the water balances of 2015-2016 (Fig. 8) with the climatic water balances (Fig. 6) at the three airports, notable differences during the autumn and winter are found. In the climatic balance the beginning of autumn shows a water deficit that is rapidly reversed during the rest of autumn and winter. Winter rains develop the reserves for the ground, since the summer is extremely dry. Only at the Menorca airport does this storage exceed the $100 \mathrm{~mm}$ threshold and therefore surface runoff and infiltration are produced. The lack of rainfall in the Balearic Islands, especially during the extreme winter of 2015-2016, gives an idea, when analyzed in terms of the water balance, of the hydrological stress to which the local vegetation was subjected. This deficit of precipitation during the winter in the Mediterranean area has been related to some more general droughts observed in Europe (Vautard et al., 2007).

It is interesting to display some other areas of Mallorca that were affected by a still more intense drought, again in terms of their water balances. Figure 11 shows the water balance for 2015-2016 obtained from the data at three automatic meteorological stations located in the south, central and northern parts of Mallorca (see Fig. 1). It can be observed that at the southernmost station (E1) the precipitation throughout the year was lower than the PET, indicating that the water deficit was accumulating during the whole hydrological year. The intense rains that affected the airport location in September did not occur in this area. The lack 

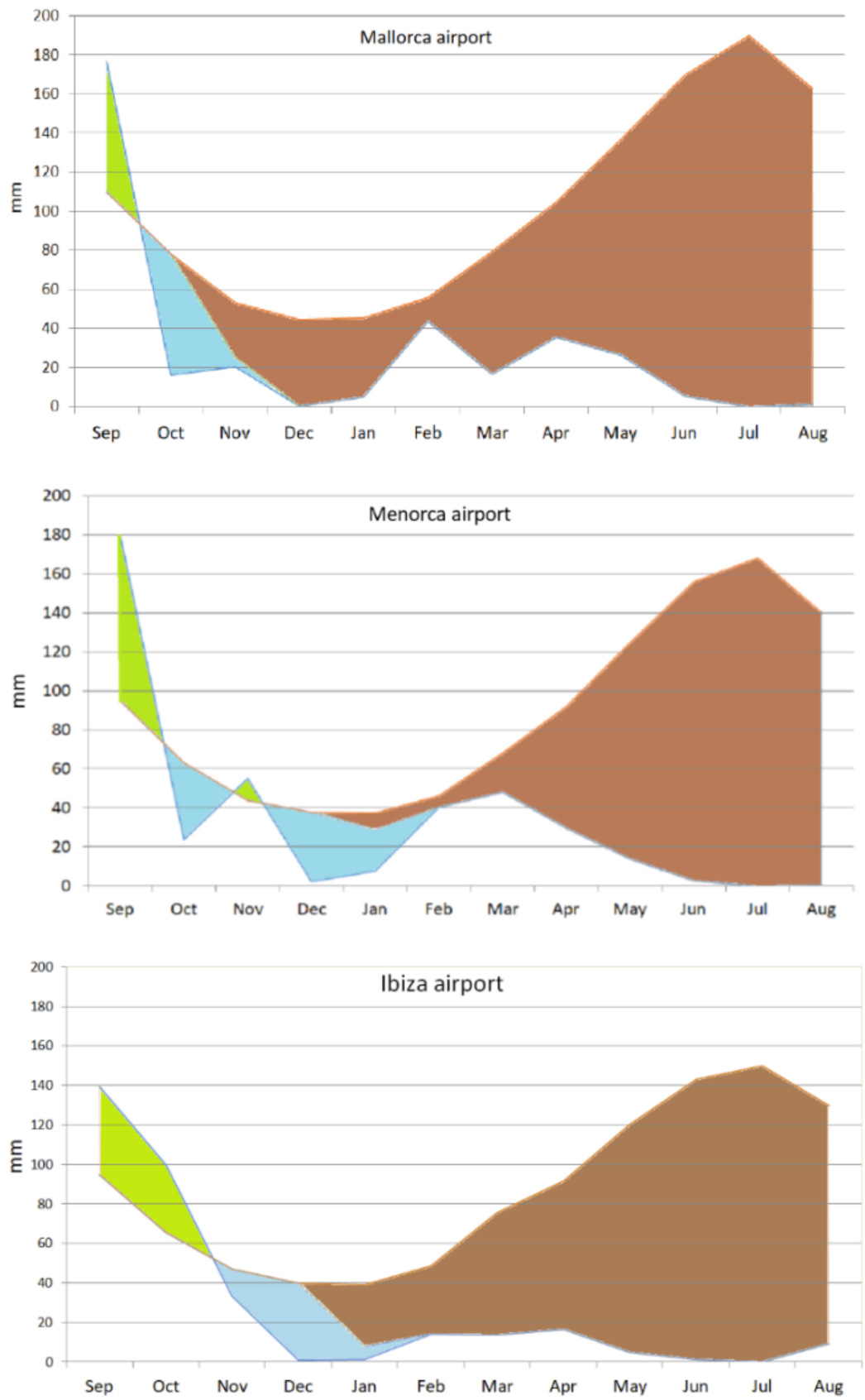

Figure 8. As in Fig. 6 but for the hydrologic year 2015-2016.

of precipitation in winter is remarkable. The accumulated drought that reached the always dry summer was very severe and had dramatic consequences on the vegetation types possessing shallow roots, as well as on some trees, especially almond, whose fruit maturation had to develop under unfavorable conditions.

The precipitation regime in the north of Mallorca (E3) was very similar to that of the southern region. Rainfall was also lower than PET during all the months of the hydrological year. In the center of the island (E2) the situation was not very different, although during the month of September the precipitation was enough to surpass the PET. The rainfall and the evaporation regimes resemble those at the airport. The convective rains of early autumn also reached the center of the island, but the profound lack of rainfall in winter was a constant that is repeated at all locations, supposing that evaporation rates permanently exceed precipitation, a feature clearly divergent from what is climatologically expected.

The hydrological year 2015-2016 was characterized by very intense rainfall events in September followed by a per- 


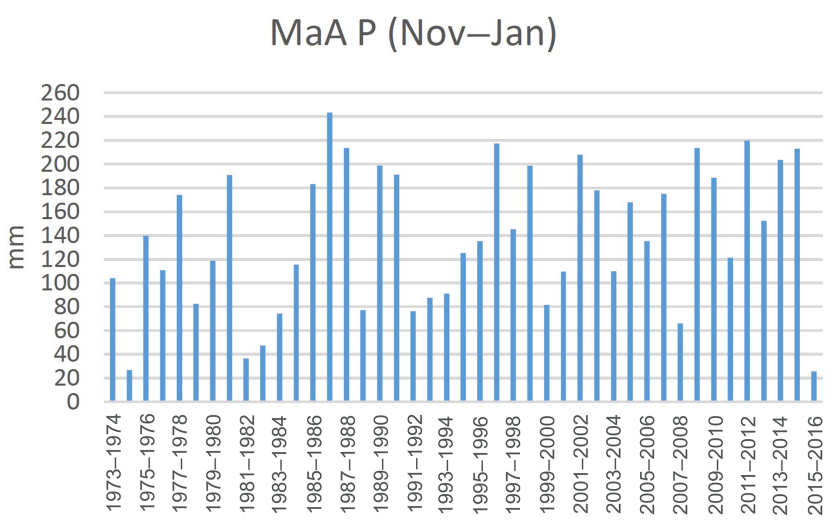

Figure 9. Accumulated precipitation from November to January at the Mallorca airport.

sistent lack of rainy situations for the rest of the period. This begs the question of the role of runoff, especially when the season starts with heavy precipitation, on soil dried out by the summer; in these conditions much less water will infiltrate and thus recharge soil moisture. There is an added problem for an accurate computation of the water balance when measurements on the runoff are not available, as is the case in our study. There are very few measurements of runoff in streams of the Balearics, all of them belonging only to special campaigns and always before 2014. Note that in the Balearic Islands there are no permanent rivers. In addition, no information about the episode can be obtained from the Earth2Observe web page, since model data extend only until 2012.

However, the runoff coefficient for a nearby stream basin to the Mallorca airport (few kilometers away) was estimated by García et al. (2017), based on observed stream flows for the 1977-2009 period. The estimated runoff coefficient was as low as 0.03 . This result ensures that the conversion of precipitation into surface runoff is quite low for this nearby basin. Furthermore, no substantial changes are found in the spatial distribution of the physiography and hydrology of the stream basin where the meteorological station is located. We can safely assume that almost all precipitation is infiltrated and that the $P-E$ balance is quite realistic when assessing the climatic water balance for the 1981-2010 period. Even for the heavy precipitation event at the end of the 2015 warm season, most precipitation would have infiltrated due to the high infiltration capacity of the soil and its low water content.

\section{Circulation patterns}

During the winter of 2015-2016 the North Atlantic was especially active cyclonically speaking. Many deep depressions developed above latitudes $45-50^{\circ}$ latitude and affected $\mathrm{Eu}-$ rope. The impact on Ireland and England was particularly great, especially in December, when very intense rains (up

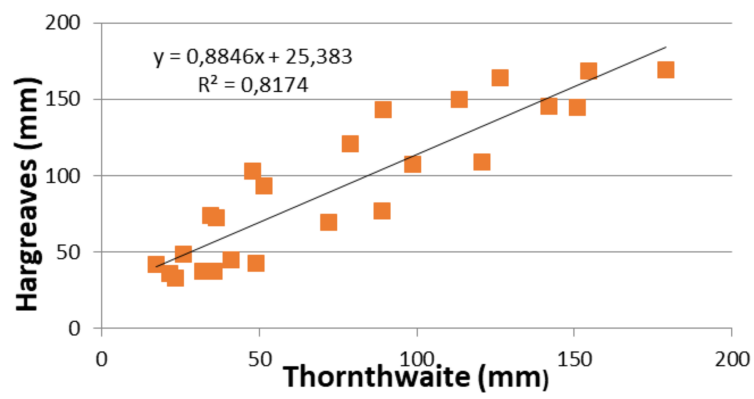

Figure 10. Comparison of the monthly PET obtained by the Thornthwaite and Hargreaves methods at E1 station (see Fig. 1) for the hydrological years 2014-15 and 2015-2016.

to $200 \%$ of the climatic value referred to $1981-2010$ for that winter; McCarthy et al., 2016) resulted in floods. The substantial westerly flow also advected warm air along that latitude belt and the mean winter climatic temperature values (period 1981-2010) were largely exceeded in Ireland and England, up to $2^{\circ}$ in the south of England. In December this warm anomaly in the south of England reached $5^{\circ}$ (McCarthy et al., 2016). This situation was caused by a strong zonal circulation of the jet stream over the North Atlantic; the jet basically pointed directly to Ireland from the coasts of America during that winter (Burt and Kendon, 2016). For latitudes below $50^{\circ}$, the westerly flow was also maintained during that winter. Figure 12 shows the average geopotential structure at $500 \mathrm{hPa}$ for Europe and the Mediterranean for November 2015 to January 2016. High geopotential values over the Iberian Peninsula and the western Mediterranean that extend towards central Europe are evident. For these months the NAO index was 3.56 for November, 4.22 for December and 1.16 for January (https://crudata.uea.ac.uk/ timo/datapages/ naoi.htm), thus reflecting a strong westerly circulation.

The above meteorological situation is unfavorable for any significant occurrence of rainfall in the western Mediterranean and particularly in the Balearic Islands. The most favorable rainfall conditions in the islands are linked with the evolution of cyclonic disturbances at mid-upper tropospheric levels which give rise to secondary depressions at surface over the Mediterranean and easterly moist flows impinging over the Balearic Islands (Romero et al., 1999). Atlantic disturbances crossing central Europe, even involving active fronts, generally produce little precipitation along the Spanish Mediterranean coast and in the Balearic Islands, in any case just affecting the northern half of the islands. Figure 13 shows that during the months of November 2015 to January 2016, when the precipitation in the Balearics was practically null, there was a strong positive anomaly of geopotential at $500 \mathrm{hPa}$ over the western Mediterranean, a circulation pattern entirely inhibiting the generation of any type of precipitation system.

It was previously reported that during September 2015 intense precipitation happened on all three islands. Figure 10 

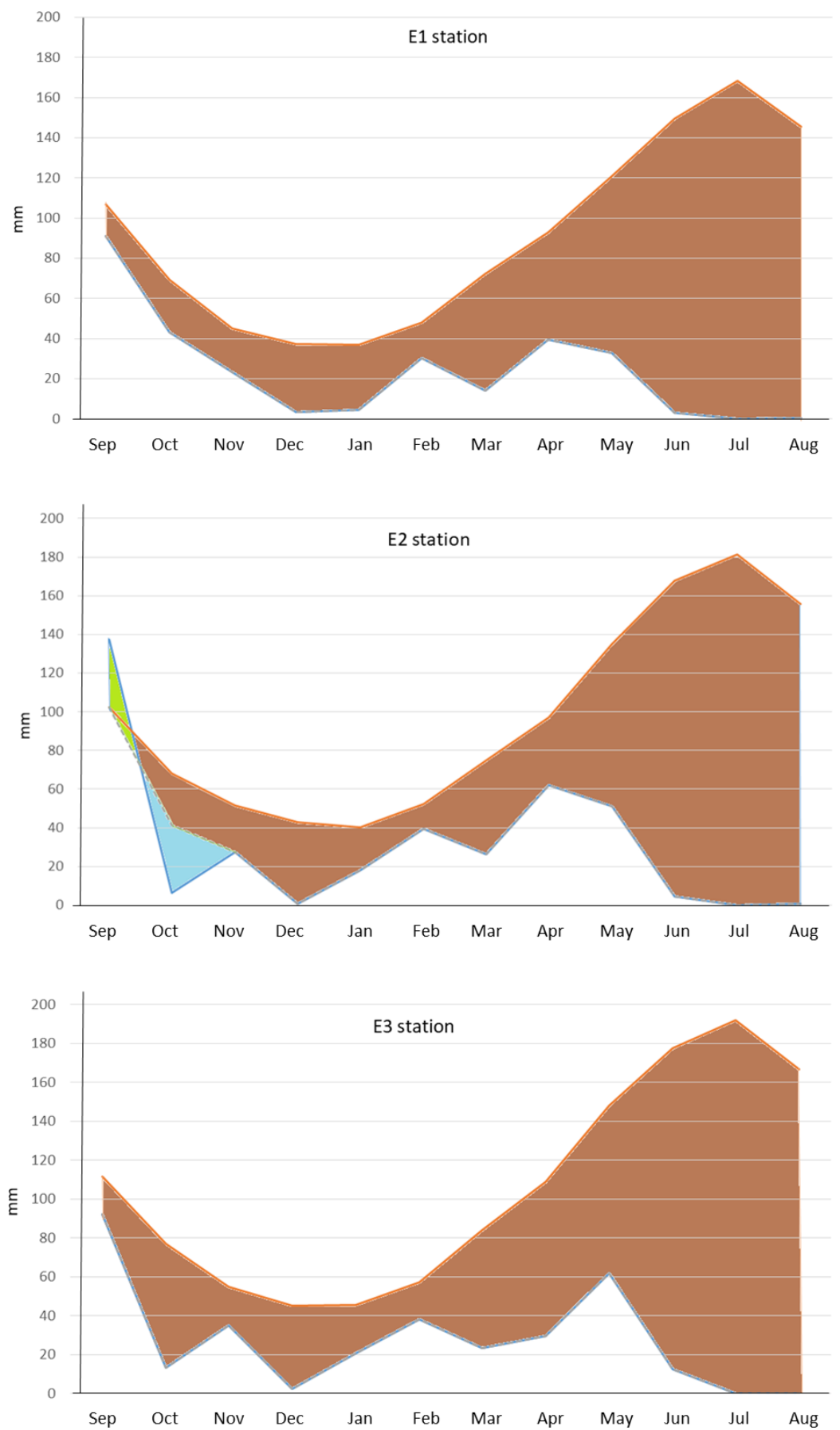

Figure 11. As in Fig. 8 but for the three additional locations in Mallorca (E1, E2 and E3 in Fig. 1).

shows that the atmospheric circulation during this month was characterized by the presence of lows at $500 \mathrm{hPa}$, indicated by the nucleus of negative anomaly affecting western Europe and the western Mediterranean. This pattern is dynamically favorable for the generation of heavy rainfall situations slightly downstream, over the Spanish Mediterranean coast and the Balearic Islands (Romero et al., 1999).
The average conditions displayed in Fig. 13 show the radical change of the circulation that occurred between September and November 2015. The pattern of September corresponds, at low levels, with the persistence of meridional flows over the north Atlantic and low NAO values $(-1.65$ for September and -1.13 In October), the opposite pattern found during the period from November 2015 to January 2016. The occurrence of rainfall in the Balearic Islands could be bet- 


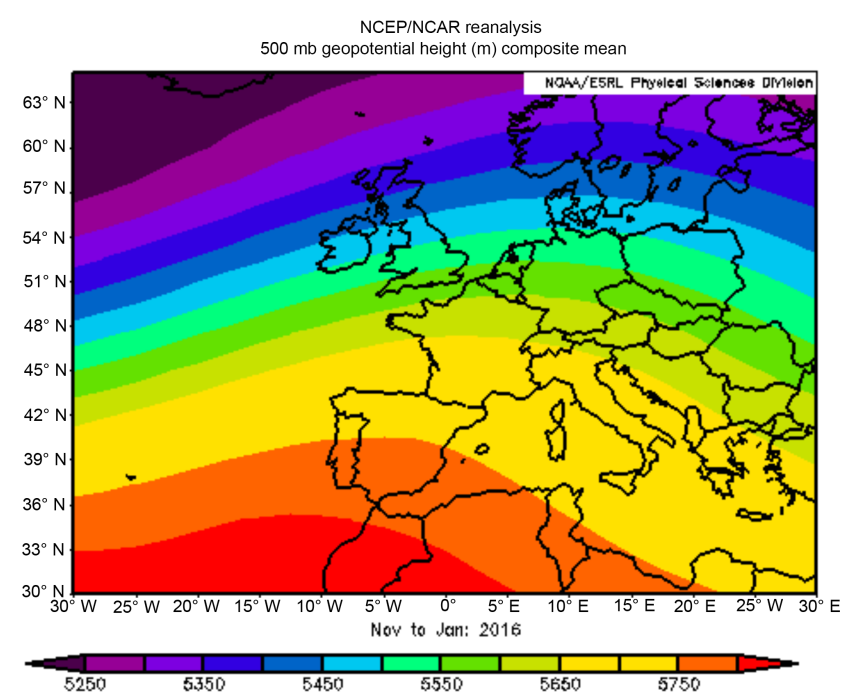

Figure 12. Mean geopotential height at $500 \mathrm{hPa}$ for November 2015-January 2016 (source NCEP/NOAA reanalysis).

ter correlated with high values of the Scandinavian Index (September 1.09, October 0.62, November -1.4, December 0.08 , January -0.68 , normalized to the period 1981-2010; http://www.cpc.ncep.noaa.gov/data/teledoc/scand.shtml).

As a contrasting situation, the hydrological year 20082009 can be considered a wet case (see Fig. 5). During the months of November to January, $214 \mathrm{~mm}$ at the Mallorca Airport, $303 \mathrm{~mm}$ at the Menorca Airport and $187 \mathrm{~mm}$ at the Ibiza Airport were recorded. Figure 14 shows the geopotential anomaly at $500 \mathrm{hPa}$ from November 2008 to January 2009. A notable negative anomaly centered over the western Mediterranean can be observed, resulting in a completely opposite pattern to that of 2015-2016 (Fig. 13). The values of the NAO index for these months were negative or low (November -1.30 , December -0.58 , January 0.6 ).

\section{Conclusions}

The characteristics of the recent drought that occurred in the Balearic Islands during the 2015-2016 hydrological year (September to August) have been presented. The analysis was carried out in terms of the particular hydrologic balance for this year using data from six meteorological stations to determine the potential evapotranspiration and to estimate the actual evaporation. These water balances have been compared against those corresponding to the long-term climatic conditions for the reference period 1981-2010. A comparison of the climatic water balance calculated with the empirical expressions against the balance deduced from eight models used by the European Earth2Observe project show some differences. Most of these differences can be attributed to the greater values of precipitation ingested in the models and the high variability of the simulated evaporation and
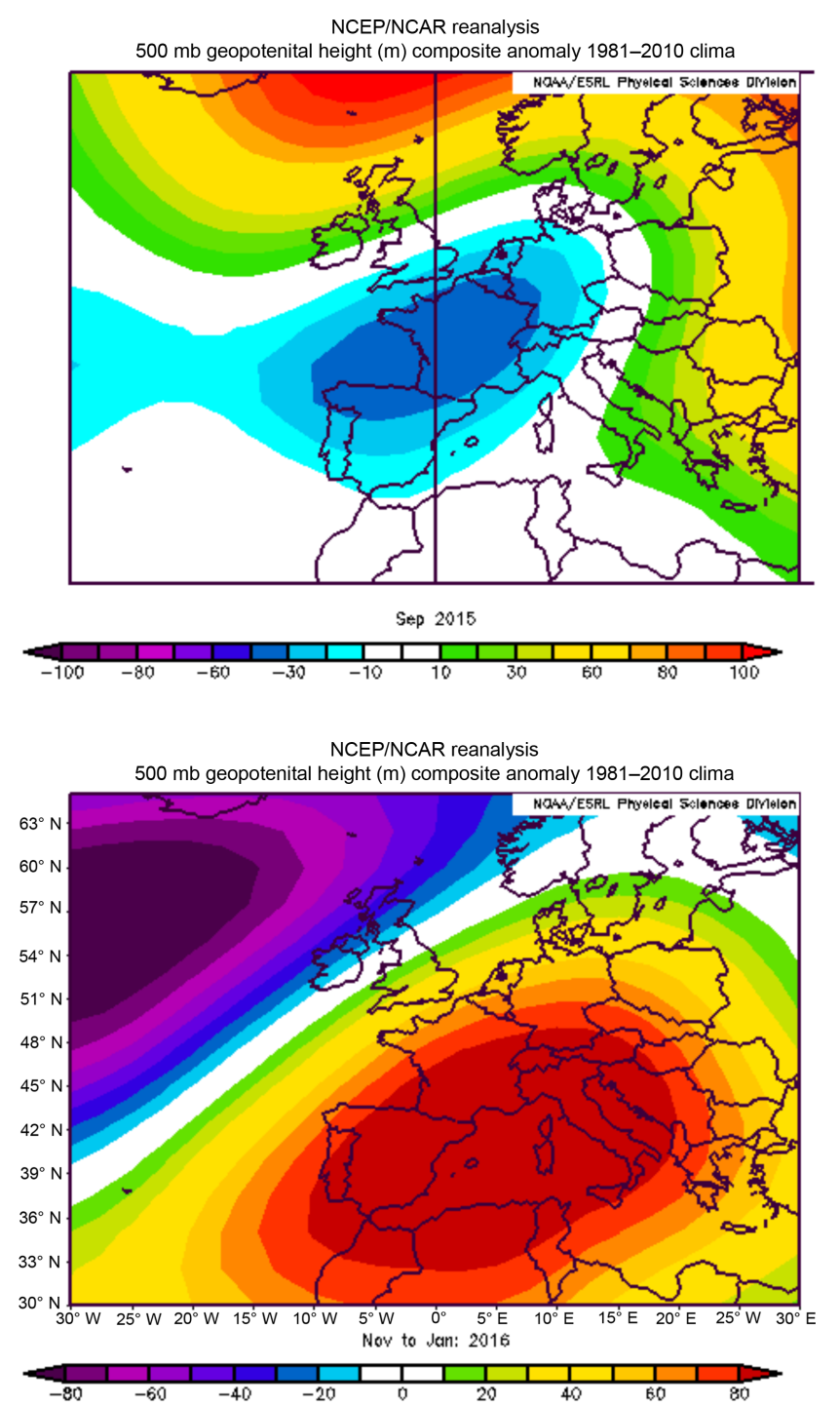

Figure 13. Geopotential height anomalies at $500 \mathrm{hPa}$ for September 2015 and for November 2015-January 2016, referring to the reference period 1981-2010 (source NCEP/NOAA reanalysis).

runoff. However, the calculated values of PET lie within the spread interval of the models.

The analyzed hydrologic year reveals a profound precipitation deficit during the winter, such that the potential evapotranspiration surpassed the precipitation practically the whole year, except in September when at some stations the precipitation exceeded the evaporation. The recorded precipitation from November 2015 to January 2016 was the lowest for this period at the three airports of the Balearic Islands for the 43 considered hydrologic years. The precipitation of December was also unappreciable in all three islands. Accordingly, the soil could not store any water to face the spring, when insolation hours and temperatures increased. This resulted in a lack of any water reserves during 2015-2016, an aspect totally anomalous compared with an average winter, 


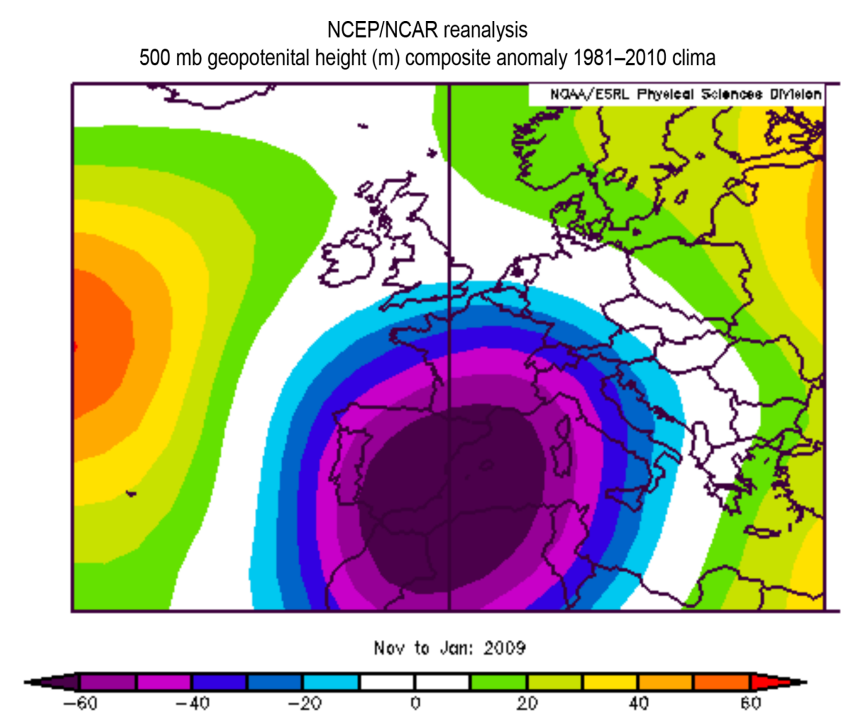

Figure 14. Geopotential height anomalies at $500 \mathrm{hPa}$ for November 2008-January 2009 with respect to the reference period 1981-2010 (source NCEP/NOAA reanalysis).

for which certain levels of moisture can be maintained in the soil until June in Mallorca and Ibiza and until July in Menorca.

We verified that the meteorological situation during the anomalous 2015-2016 winter was dominated by a very marked westerly flow over the North Atlantic, with high values of the NAO index. This situation caused intense precipitations and anomalously warm temperatures in Ireland and England. In contrast, precipitation at lower latitudes, and particularly in the western Mediterranean, was very scarce.

The identification of anomalous circulation patterns in seasonal or climate prediction models can be a mechanism for anticipating drought situations and stimulate planning and mitigation measures in a region like the Mediterranean, where water demand is high, especially at the time of the year when precipitation is scarce. It is also a promising line of research for purposes of agricultural planning and conservation of the current vegetation.

Data availability. Temperature and precipitation data used in this work were recorded by the Spanish Meteorological Agency (AEMET). The agency can provide data under request.

Competing interests. The authors declare that they have no conflict of interest.

Acknowledgements. The weather analyses correspond to the NCEP/NOAA reanalysis database (https://www.esrl.noaa.gov/psd/ cgi-bin/data/composites/printpage.pl). Figure 3 comes from the PREGRIDBAL project (http://pregridbal-v1.uib.es/). References to media correspond to Diario de Mallorca. The authors acknowledge the reviewers for their constructive comments that contributed to improve the original version of the paper. This research was sponsored by CGL2014-52199-R (EXTREMO) project, which is partially supported with FEDER funds, an action funded by the Spanish Ministerio de Economía y Competitividad.

Edited by: Vassiliki Kotroni

Reviewed by: Jan Polcher and one anonymous referee

\section{References}

Barceló, M.: Per a una aproximació a la climatologia de Mallorca baix medieval a través dels textos històrics, Bull. Soc. Arqueològica Luliana, 47, 123-140, 1991.

Beck, H. E., van Dijk, A. I. J. M., Levizzani, V., Schellekens, J., Miralles, D. G., Martens, B., and de Roo, A.: MSWEP: 3hourly $0.25^{\circ}$ global gridded precipitation (1979-2015) by merging gauge, satellite, and reanalysis data, Hydrol. Earth Syst. Sci., 21, 589-615, https://doi.org/10.5194/hess-21-589-2017, 2017.

Botey, R. and Moreno, J. V.: Metodología para estimar la humedad del suelo mediante un balance hídrico exponencial diario, AEMET, 22 pp., Madrid, 2015.

Burt, S. and Kendon, M.: December 2015 - an exceptionally mild month in the United Kingdom, Weather, 71, 314-320, 2016.

García, C., Amengual, A., Homar, V., and Zamora, A.: Losing water in temporary streams on a Mediterranean island: Effects of climate and land-cover changes, Global Planet. Change, 148, 139152, 2017.

Gaussen, H.: Détermination des climats par le méthode des courbes ombrothermiques, Comptes Rendus Hebdomadaires des Seances de l'Academie des Sciences, 240, 642-643, 1955.

Guijarro, J. A.: Bioclimatología de las Baleares, Tesis doctoral, Univ. Illes Balears, 1986.

Guijarro, J. A.: Tendencias de la precipitación en el litoral mediterráneo español, in: El agua y el clima, edited by: Guijarro, J. A., Grimalt, M., Laita, M., and Alonso, S., Asociación Española de Climatología, A-3, 237-246, 2002.

Guijarro, J. A.: El flujo geostrófico superficial en el Mediterráneo Balear durante el periodo 1948-2002, Rev. Climatol., 3, 45-59, 2003.

Hargreaves, G. H. and Samani, Z. A.: Reference crop evapotranspiration from temperature, Appl. Eng. Agric., 1, 96-99, 1985.

Hoerling, M., Eischeid, J., Perlwitz, J., Quan, X., Zhang, T., and Pegion, P.: On the Increased Frequency of Mediterranean Drought, J. Climate, 25, 2146-2161, 2012.

Homar, V., Ramis, C., Romero, R., and Alonso, S.: Recent trends in temperature and precipitation over the Balearic Islands (Spain), Climatic Change, 98, 199-211, 2010.

Jansà, A.: El Clima de les Illes Balears, Lleonard Muntaner Ed., 93 pp., Palma de Mallorca, 2014.

Jansà, A., Homar, V., Romero, R., Alonso, S., Guijarro, J. A., and Ramis, C.: Extension of summer climatic conditions into spring in the western Mediterranean area, Int. J. Climatol., 37, 19301950, https://doi.org/10.1002/joc.4824, 2017.

López Mayol, T., Homar, V., Ramis, C., and Guijarro, J. A.: PREGRIDBAL 1.0: towards a high-resolution rainfall atlas for the 
Balearic Islands (1950-2009), Nat. Hazards Earth Syst. Sci., 17, 1061-1074, https://doi.org/10.5194/nhess-17-1061-2017, 2017.

McCarty, M., Spillane, S., Walsh, S., and Kendon, M.: The meteorology of the exceptional winter 2015/2016 across the UK and Ireland, Weather, 71, 305-313, 2016.

McKee, T. B., Doesken, N. J., and Kleist, J.: The relationship of drought frequency and duration to time scales, Preprints of Eight Conf. on Applied Climatology, Anaheim CA, Amer. Meteorol. Soc., 179-184, 1993.

Palmer, W. C.: Meteorological drought, U.S. Department of Commerce Weather Bureau Research Paper 45, 58 pp., 1965.

Peel, M. C., Finlayson, B. L., and McMahon, T. A.: Updated world map of the Köppen-Geiger climate classification, Hydrol. Earth Syst. Sci., 11, 1633-1644, https://doi.org/10.5194/hess-11-16332007, 2007.

Peñuelas, J., Lloret, F., and Montoya, R.: Severe Drought Effects on Mediterranean Woody Flora in Spain, Forest Sci., 47, 214-218, 2001.

Rind, D., Goldberg, R., Hausen, J., Rosenzweig, R., and Ruedy, R.: Potential evapotranspiration and the likelihood of future drought, J. Atmos. Res.-Atmos., 95, 9983-10004, 1990.
Romero, R., Sumner, G., Ramis, C., and Genovés, A.: A classification of the atmospheric circulation patterns producing significant daily rainfall in the Spanish Mediterranean area, Int. J. Climatol., 19, 765-785, 1999.

Sumner, G., Guijarro, J. A., and Ramis, C.: The impact of surface circulation on significant daily rainfall patterns over Mallorca, Int. J. Climatol., 15, 673-696, 1995.

Thornthwaite, C. W.: An Approach toward a Rational Classification of Climate, Geogr. Rev., 38, 55-94, 1948.

Vautard, R., Yiou, P., D’Andrea, F., de Noblet, N., Viovy, N., Cassou, C., Polcher, J., Ciais, P., Kageyama, M., and Fan, Y.: Summertime European heat and drought waves induced by wintertime Mediterranean rainfall deficit, Geophys. Res. Lett., 34, L07711, https://doi.org/10.1029/2006GL028001, 2007.

Vicente-Serrano, S. M., González-Hidalgo, J. C., de Luis, M., and Raventós, J.: Drought patterns in the Mediterranean area: the Valencia region (eastern Spain), Climate Res., 25, 5-15, 1994. 